In: ISMÉRIO, Clarisse (Org.). Patrimônio Cultural: simbolismos, intertextualidades e polifonias [livro eletrônico]. São Paulo: Vecher, 2021. Disponível em: <https://doi.org/10.47585/9786599324215>.

\title{
Novo Sarau Noturno: do presencial ao virtual
}

\section{Clarisse Ismério ${ }^{1}$, Amanda Couto ${ }^{2}$ e Darlan Rosa ${ }^{3}$}

doi.org/10.47585/9786599324215.2

O projeto Cultural Sarau Noturno, criado em 2008, com o objetivo de contar a história da cidade de Bagé/RS, aproximar a comunidade local da riqueza presente no Cemitério da Santa Casa de Caridade e assim promover a preservação da arte cemiterial, consagrou-se então através de apresentações presenciais, pesquisas e publicações. Iniciou o ano de 2020, enfrentando o desafio de adaptar-se à atipicidade causada pela pandemia de Covid-19. Essa mudança era necessária para que o evento continuasse sua proposta, assim apresentamos o processo de reinvenção virtual do novo Sarau Noturno. Munidos de desafios permeados desde sua concepção estética, formal e funcional, destaca-se o papel da educação patrimonial e o valor histórico-cultural presente nos túmulos, jazigos, estátuas e símbolos, tendo em vista o valor imaterial presente no espaço cemiterial.

Palavras-chave: Educação; Patrimonial; Arte; Cemiterial; Virtualização.

\footnotetext{
1 Historiadora, Doutora em História do Brasil pela PUC-RS. Professora e Pesquisadora do Centro Universitário da Região da Campanha - Urcamp. Coordenadora do Sarau Noturno, http://lattes.cnpq.br/4600253785089001, e-mail: clarisseismerio@urcamp.edu.br.

2 Acadêmica do Curso de Direito do Centro Universitário da Região da Campanha - Urcamp. Voluntária do projeto Sarau Noturno, http://lattes.cnpq.br/5342403955563312, e-mail: amandacouto189165@sou.urcamp.edu.br.

3 Acadêmico do Curso de Arquitetura e Urbanismo do Centro Universitário da Região da Campanha - Urcamp. Voluntário do projeto Sarau Noturno, http://lattes.cnpq.br/6908906852584130, e-mail: darlanrosa190142@sou.urcamp.edu.br
} 


\section{Introdução}

Em 2008, foi criado o Sarau Noturno, um evento de educação patrimonial criado para valorizar a arte cemiterial e para aproximar a comunidade local da riqueza presente no Cemitério da Santa Casa de Caridade de Bagé, Rio Grande do Sul. Trata-se de um evento consolidado, do qual participam acadêmicos de vários cursos do Centro Universitário da Região da Campanha - Urcamp. Durante os anos de atuação, de 2008 a 2019, o Sarau Noturno brindou ao público apresentações que destacavam a importância histórica e artística do local.

Mas, o ano de 2020 foi extremamente desafiador, pois, em virtude do isolamento social decorrente da pandemia da Covid-19, forçou uma readequação do Sarau Noturno aos novos tempos. Foi criada uma nova proposta de apresentação, um novo roteiro, cenário virtual adaptado e apresentação através da rede social YouTube. Assim apresentamos, nestas breves páginas, o processo de reinvenção do Sarau Noturno para a linguagem cênica virtual.

\section{O novo Sarau Noturno}

Os cemitérios, originalmente, foram criados para abrigar os mortos, mas com o tempo transformaram-se em instituições culturais. Verdadeiros museus a céu aberto que devem ser "visitados e admirados pelas obras de arte neles contidas, obras essas que eram muitas vezes representativas do que de melhor se fazia na época”. (QUEIROZ, 2007, p. 1)

Diante da importância desses espaços de memória, iniciamos no ano de 2007 a pesquisa História através da Arte Cemiterial, buscando dados dos túmulos e mausoléus do acervo do Cemitério da Santa Casa de Caridade de Bagé4. A investigação em fontes cemiteriais é bastante rica e, segundo Bellomo (2000), nos permite reconstituir a história das sociedades por meio de múltiplas nuances como crenças religiosas, ideias e posturas políticas, estética artística, formação étnica do município, expectativa de vida da população, além de propiciar o desenvolvimento de estudos genealógicos. Metaforicamente, o cemitério pode ser comparado a um livro e cada túmulo é um capítulo que narra as histórias e os imaginários socais.

Cabe destacar que o Sarau Noturno fundamenta-se na Educação Patrimonial, para promover a valorização e preservação do acervo artístico e arquitetônico, pois propicia a "ativação da memória social, recuperando conexões e tramas perdidas [...], promovendo a apropriação pelas comunidades de sua herança cultural, resgatando ou reforçando a autoestima e a capacidade de identificação dos valores culturais." (HORTA, 2000, p. 35).

Maria Elizia Borges, grande pesquisadora dos estudos cemiteriais no Brasil, enfatiza

4 O Cemitério da Santa Casa de Bagé, de 1858, possui um conjunto de túmulos de invejável valor histórico. Em seu acervo, estão figuras notórias da sociedade, envolvendo mausoléus de famílias tradicionais e de heróis da Revolução Farroupilha e da Guerra do Paraguai. Esse cemitério guarda uma parte da história da "Rainha da Fronteira" (apelido da cidade de Bagé), que pode ser contada por intermédio de seus vultos históricos, das representações simbólicas e pela releitura promovida pelo imaginário social (ISMĖRIO, 20216). 
a importância e vanguarda da proposta do Sarau Noturno, ao reconhecer que "foi pioneiro no Brasil e conta com a participação de alunos universitários que realizam performances bem complexas: representam personagens da literatura romântica vestidos à caráter; declamam poesias, cantam trechos musicais e teatralizam o contexto histórico bajeense à medida que adentram o cemitério." (apud ISMÉRIO, 2016, p. 14) ${ }^{5}$.

Trata-se de uma teatralização cujo roteiro mescla vultos históricos de Bagé com passagens e personagens da literatura romântica. Assim, as personalidades locais, como o João da Silva Tavares (Visconde de Cerro Alegre) ${ }^{6}$, o General Antônio de Souza Netto ${ }^{7}$ ou o comerciante filantropo Francisco Ilarregui ${ }^{8}$, dividem o cenário com Hamlet, Ofélia, Henrique $\mathrm{V}$ e Lisístrata. A escolha dos personagens ocorreu presença marcante, força simbólica e por melhor se integrar as passagens propostas.

Mas em 2020, em que vivemos um período de exceção provocado pela pandemia da Covid-19, onde estamos imersos num tempo marcado por telas de computador, links de vídeo conferências, lives e ensino remoto, o Sarau Noturno se reconfigura para entrar no universo virtual.

Constituindo-se como um projeto cultural de ensino, atualmente é formado pelas(os) acadêmicas(os) Amanda Antunes do Couto (Direito), Amanda Aires Bispar (Direito), Ana Carolina Moraes da Silva (Ciências Biológicas), Camila Barcellos (Direito), Darlan Almeida da Rosa (Arquitetura), Kátia Silene Antunes da Silva (História), Mateus Mesk Ferreira (Psicologia), Raiana Lima Barreto (Ciências Biológicas), Thanise Maçã Machado Miranda (Ciências Biológicas), Vinícius Rodrigues Ferreira (Arquitetura) e Vivian Torbes (Nutrição).

A esse grupo coube o desafio de reinventar o Sarau Noturno, buscando além da valorização do patrimônio, uma visão social da arte cemiterial refletida sob a característica de suas áreas de formação. O roteiro foi alterado com o acréscimo da personagem que conta a história de Luciana Lealdina de Araújo, mais conhecida como mãe Luciana, que dedicou sua vida para caridade. Em

\footnotetext{
5 Conforme também destaca a pesquisadora, “as visitas guiadas em cemitérios no período noturno, acompanhadas com programações artísticas, foram iniciadas há pouco tempo no Brasil. Em 2014, foi implantado o projeto Memória e Vida Consolação, no Cemitério da Consolação (1858) em São Paulo. A Pontifícia Universidade Católica de São Paulo e o Serviço Funerário Municipal estão realizando práticas culturais diversas, com o objetivo de inovar o uso do espaço cemiterial com apresentações noturnas de música, peças de teatro e projeção de filmes. Essa proposta é muito similar às que preveem os programas denominados 'noite de Lua Cheia', realizados nos cemitérios museus instalados nas cidades latino-americanas de Medellín (Colômbia) e Lima (Peru).” (BORGES apud ISMÉRIO, 2016, p. 14).

6 João da Silva Tavares, o Visconde de Cerro Alegre, comandante da divisão de cavalaria do Exército Imperial Brasileiro, é um dos nobres da história de Bagé. Recebeu seus títulos nobiliários pelos serviços prestados à monarquia e pela lealdade dedicada ao Império. Em 1859, ganhou o de "Barão de Serro Alegre” e, em 1870, ao final da Guerra do Paraguai, lhe foi auferido o título de "Visconde com Grandeza". Essa distinção autorizava usar em seu brasão de armas a coroa do título superior, no caso o de conde. Por seus feitos também recebeu as comendas de Comendador da Ordem de Cristo e Cavaleiro da Ordem de Aviz. (ISMÉRIO, 2016, p. 44-45).

7 Apesar de seu perfil militar, tendo participado da Revolução Farroupilha (1835-1945) e da Guerra do Paraguai (1864-1870), não foi representado como um general em seu leito de morte. Pelo contrário, foi eternizado iconograficamente como um herói ilustrado que, ao invés da farda, veste terno e gravata, símbolos de sobriedade e elegância na época. (ISMÉRIO, 2016, p. 37). 8 Imigrante espanhol que prosperou através de atividades ligadas ao comércio e tornou-se uma figura de destaque na sociedade bajeense, era considerado "[...] um cavalheiro respeitável, de caráter austero e muito concentrado ao trabalho, conseguindo à custa de incessante labor adquirir honestamente uma regular fortuna.” (ISMÉRIO, 2016, p. 45).
} 
1901, criou o Asilo de Órfãs São Benedito, em Pelotas, "com o objetivo de amparar e instruir meninas pobres desvalidas, ou seja, órfãs, enjeitadas." (CALDEIRA, 2014, p. 114). Contar sua história sob o olhar do Sarau Noturno é valorizar a vida e obra dessa mulher impar, que hoje descansa num modesto túmulo do Cemitério da Santa Casa de Caridade de Bagé.

Nos cemitérios as imagens femininas são predominantes, porém elas evidenciam a submissão feminina ao serem representadas por carpideiras, alegorias e musas, foram ressaltadas somente as virtudes femininas, uma característica do ideário positivista que na "arte deve representar uma imagem ideal a ser seguida, cultivando com isso o aperfeiçoamento humano." (ISMÉRIO, 2019, p. 57). Porém, no Sarau Noturno, as representações femininas são protagonistas com voz ativa para denunciar e lutar contra os cativeiros impostos pelo patriarcado ao longo da história. Trata-se de uma homenagem às professoras, jornalistas, poetisas e literatas dos séculos XIX e XX, que lutaram pelos direitos das mulheres.

A proposta do novo Sarau Noturno foi apresentada em um evento online no dia 15 de agosto de $2020^{9}$. A noite iniciou com palestra da Dra. Fernanda Pedrazzi, docente da UFSM, com o tema "A importância dos cemitérios como guardiões do patrimônio". E, na segunda parte, os integrantes do Sarau Noturno apresentaram seus personagens (Figura 1).

Figura 1: Palestra e apresentação da proposta do novo Sarau Noturno.
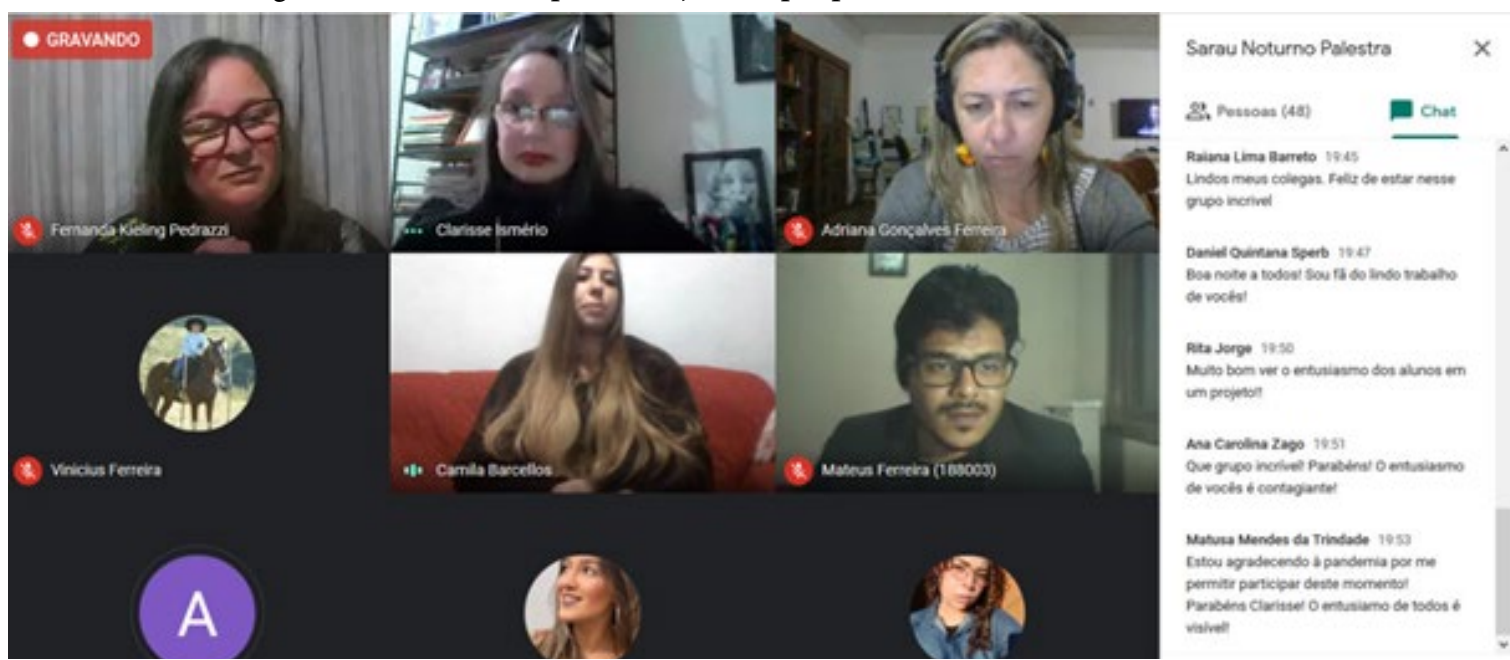

Fonte: acervo do projeto.

O evento foi nitidamente um sucesso e estiveram presentes prestigiando-o os integrantes da Associação Brasileira de Estudos Cemiteriais (ABEC), da Rede Ibero-americana de Estudos Cemiteriais, mestrandos do Programa de Pós-Graduação de Patrimônio Cultural da Universidade Federal de Santa Maria, o consultor Daniel Sperb, professoras, acadêmicas(os) da Urcamp e comunidade.

O coordenador do Curso de Farmácia da Urcamp, Dr. Guilherme Cassão Marques Bragança, deu um depoimento emocionado relatando sua participação no Sarau Noturno, pois atuou na construção,

9 Esse evento foi proposto pelo acadêmico Darlan Almeida da Rosa e acolhido por todos os componentes do grupo. 
tanto no processo de coleta de dados da pesquisa como nas apresentações como violinista.

\begin{abstract}
O Sarau Noturno é a mais encantadora expressão da cultura, arte e preservação do patrimônio histórico. No Sarau, as verdades de outrora ressurgem e ganham vida em uma contemplação pura e bela de existências que marcaram épocas, de amores que guardaram saudades. Fazer parte deste lindo e sem igual projeto é uma lisonja que seria indefinível apenas com palavras, pois o sarau é sentido, é vivido! A gratidão que trago no coração é imensa. A Professora Clarisse com sua essência histórica nos trouxe o futuro. Apresentou à comunidade o maior e mais relevante projeto de valorização cultural dos nossos museus a céu aberto, dos nossos templos individuais - as moradas reais - que na eternidade guardam a base que em idos tempos estruturaram as viagens ainda planificadas numa história hoje revivida. Confesso, com o coração repleto de carinho, que não só faço parte do Sarau Noturno, mas sim, ele é parte de mim! Ele guarda seu lugar em meus dias, em minha alma, em meu coração, em meu pensamento. Nele, vivo lindas lembranças que em mim ele faz serem vida! (BRAGRANÇA, Guilherme C. M., 2020)
\end{abstract}

A partir daí, a equipe de marketing, composta por Amanda do Couto, Ana Carolina Moraes e Darlan Almeida, começou a produzir peças de divulgação. Utilizou-se um método de divulgação efetiva, visando levar a conhecimento do público pequenos fragmentos dos monólogos de cada personagem, durante vídeos curtos de no mínimo 1 minuto (Figura 2) e artes que enfatizaram o acervo cemiterial presente no Cemitério da Santa Casa de Bagé, ao passo que revelassem a nossa identidade visual e provocassem não só apelo e curiosidade, mas consciência da detenção deste espaço como ambiente material e imaterial, guardião da memória, história e cultura local.

Figura 2: Vídeos de divulgação para o dia 31 de Outubro.
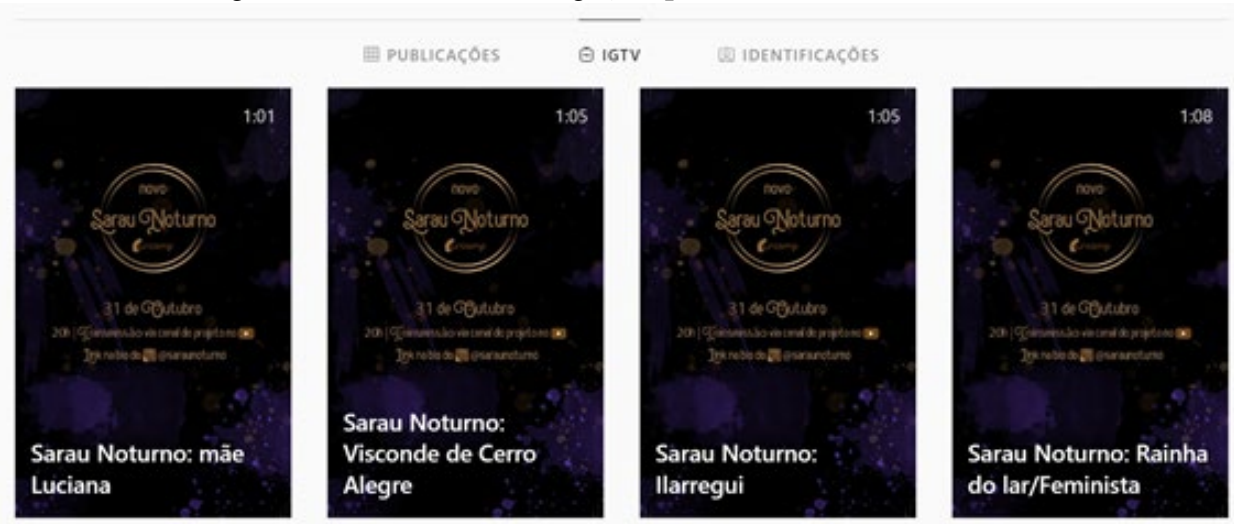

Fonte: acervo do projeto.

A necessidade de instigar o público a conhecer e reconhecer o projeto se consagra com a idealização dos teasers de divulgação durante a última semana, que antecedeu a apresentação. Assim, além de reinventar os trejeitos e representações cênicas dos personagens através do audiovisual, destacase que o mesmo permite dar novas roupagens e ambientações mediante os recursos luminotécnicos e/ ou sonoros durante a pré e pós produção dos vídeos. O meio de explanação inicial dos vídeos se deu através da ferramenta IGTV ${ }^{10}$, proporcionada pelo Instagram.

10 IGTV, ou Instagram TV, é uma ferramenta proporcionada pela plataforma Instagram que possibilita a postagem de vídeos mais longos, de no mínimo 1 minuto e máximo de 60 minutos, e com dimensões diferentes do padrão de postagem. 
Foram criadas chamadas para o Facebook e Instagram institucionais e do próprio Sarau Noturno, com imagens de jazigos, estátuas e símbolos (Figura 3), além de uma contagem regressiva explicitando alguns dos personagens, até o dia da apresentação (Figura 4).

Figura 3: Artes de divulgação para o dia 31 de outubro.

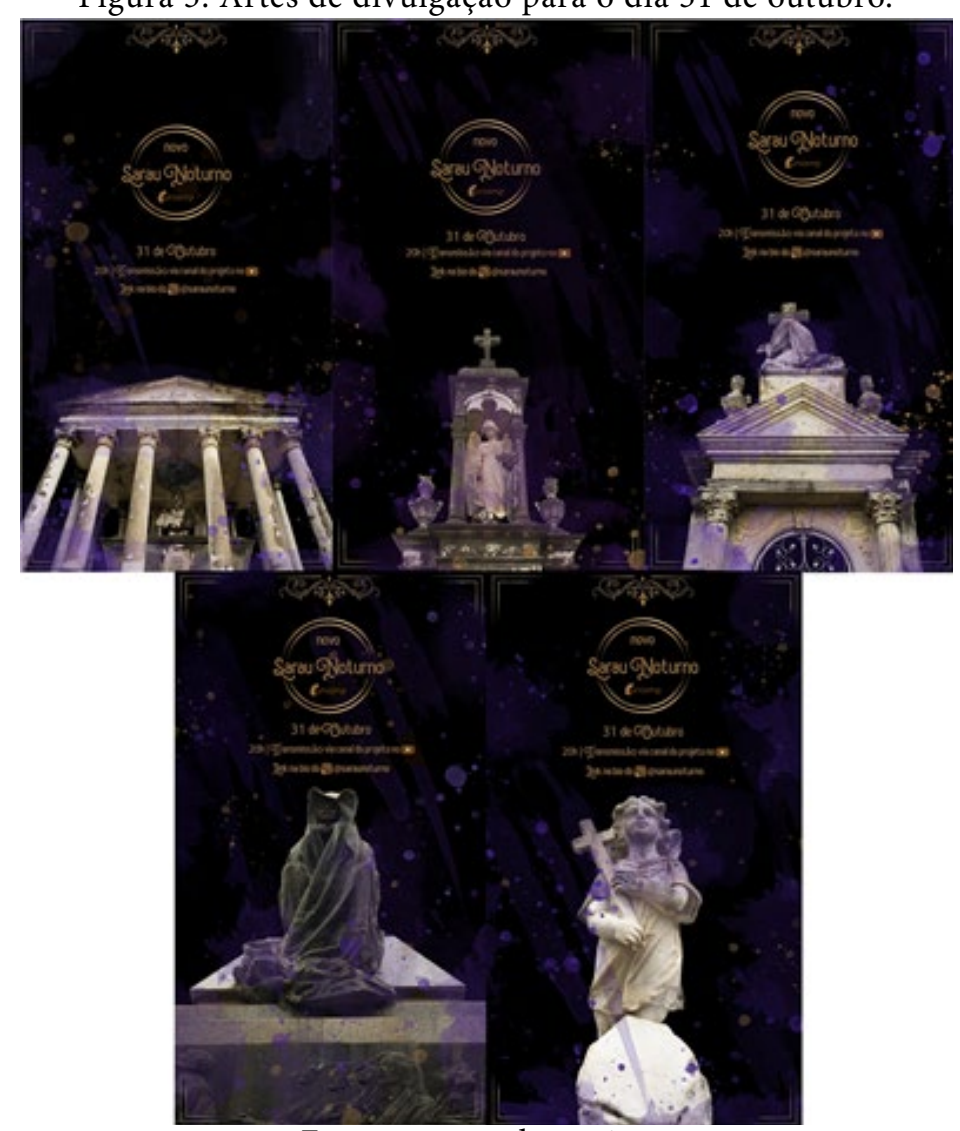

Fonte: acervo do projeto.

Imagem 4: Contagem regressiva para o dia 31 de outubro.

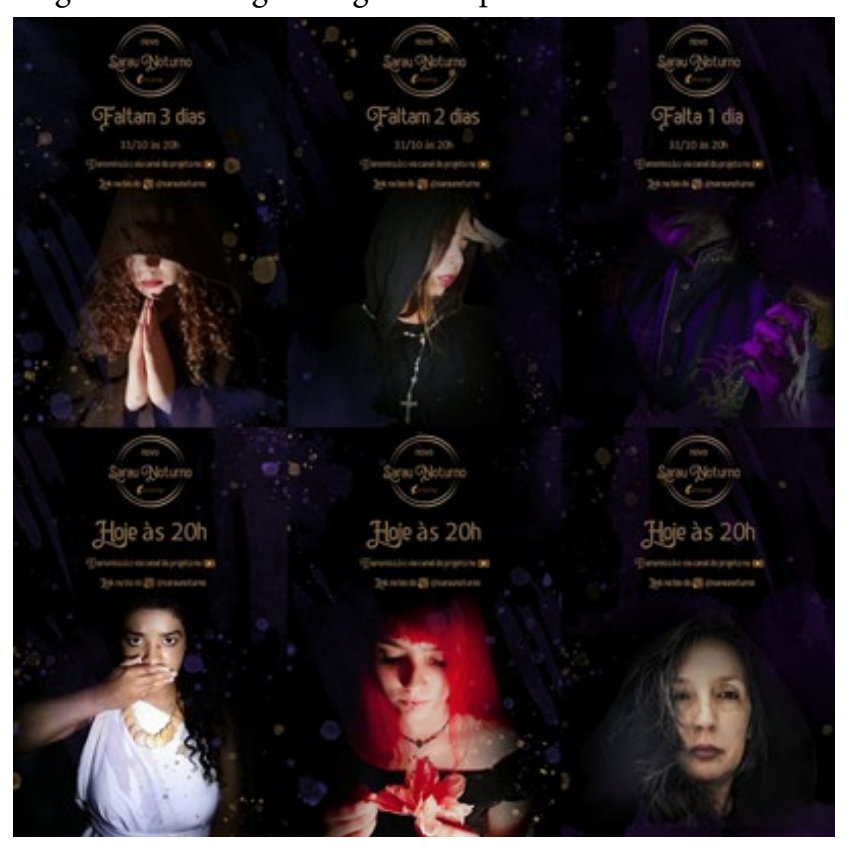

Fonte: acervo do projeto. 
E para a inserção no universo cyber foi criado um cenário virtual, utilizando a ferramenta OBS Studio ${ }^{11}$ somado à ferramentas de manipulação, tratamento e pós-produção de imagem, alicerçado na plataforma do Google Meet para ser transmitida via YouTube em uma live. A plataforma de vídeo pré-estabelecida proporciona as usuais videoconferências, um meio visual mais direto e pessoal, onde a presença de cada personagem se daria de maneira inteiramente desprovida de contextualizações e ambientações, revelando demais o 'por de trás das cortinas'. Destarte, demonstrava-se restrito e dependente do espectador, tendo em vista o caráter autônomo de acessibilidade da própria ferramenta, o que exigia do público uma compreensão a respeito do manuseio e um conhecimento da cronologia a ser apresentada. Tais pontos afastam dos produtores o controle da experiência, que em contraponto a um produto audiovisual que possui um aspecto individual em sua produção, também gera percepções subjetivas e mutáveis de acordo com as individualidades múltiplas, sendo assim, necessitava-se de um veículo que refletisse tal qual como um construto cinematográfico em sua exibição.

Colocando em evidência a necessidade de promover uma imersão controlada no modo de apresentação do evento, pensou-se em possibilidades que abrangessem e colaborassem para a ambientação dos monólogos e simbologias do espaço cemiterial, sem perder o dinamismo. A plataforma de videoconferência pré-estabelecida, estagnava os objetivos propostos: desmistificação, desconstrução e, principalmente, a ambientação das falas que aludem aos túmulos existentes no Cemitério da Santa da Casa de Caridade de Bagé.

Com isso, o pilar inicial, a imersão, norteou o desenvolvimento do veículo de apresentação, antes por videoconferência e agora via transmissão igualmente em tempo real, devidamente munidos de ferramentas criativas que permitiram não só apoiar a identidade visual concebida, mas igualmente a sua ambientação, buscadas para este fim, onde o aspecto subjetivo prevalece, porém inalterado em sua essência, afinal os produtores, por sua vez, mantiveram o controle por trás dos bastidores.

Ambientar os monólogos e cada personagem, com base em sua posição física no evento presencial, foi imprescindível junto à unidade e concepção estética padrão criada. As questões simbólicas tocantes à arte cemiterial se fazem presentes da mesma forma que o ambiente presencial, com seus túmulos ao lado e ambientados por fundos semelhantes. Assim, possibilitamos que os telespectadores além de encararem o evento como uma peça de teatro virtual e também o entendessem como um pequeno filme. A divisão em atos, correlacionados entre si, bem como a apresentação ao vivo, aludem ao ambiente teatral, mas a colocação dos recursos digitais, somada a possibilidade de revisitar este ambiente posteriormente, trazem o espírito cinematográfico e a conscientização acerca do acervo

11 Open Broadcaster Software, ou OBS Studio, é um software de transmissão e gravação gratuito. O mesmo permite total personalização e customização dos veículos de indexação dos personagens, onde além de ambientar os aspectos cênicos, climatizou-se e creditou-se igualmente a uma nomenclatura cinematográfica, afinal, desprendido de seu caráter físico, o conjunto inteiro do programa fez com que o produto final pudesse ser alterado de acordo com as necessidades e programações visuais que foram e serão produzidas. 
cemiterial de valor histórico, simbólico e cultural contido nos túmulos, jazigos e estátuas ao levar para o âmbito digital, as experiências do museu a céu aberto.

Em virtude de tais objetivos e aspirações, ressalta-se a importância do constante aprendizado mútuo do grupo a partir dos ensaios semanais com lives privadas no canal do YouTube do projeto, assim, praticando o uso das ferramentas escolhidas onde resguardou-se um acervo de material digital (Figura 5 e 6), obtido para posteriores análises, entendimentos e remodelagens se necessário.

Figuras 5 e 6: Acervo digital dos ensaios e testes.

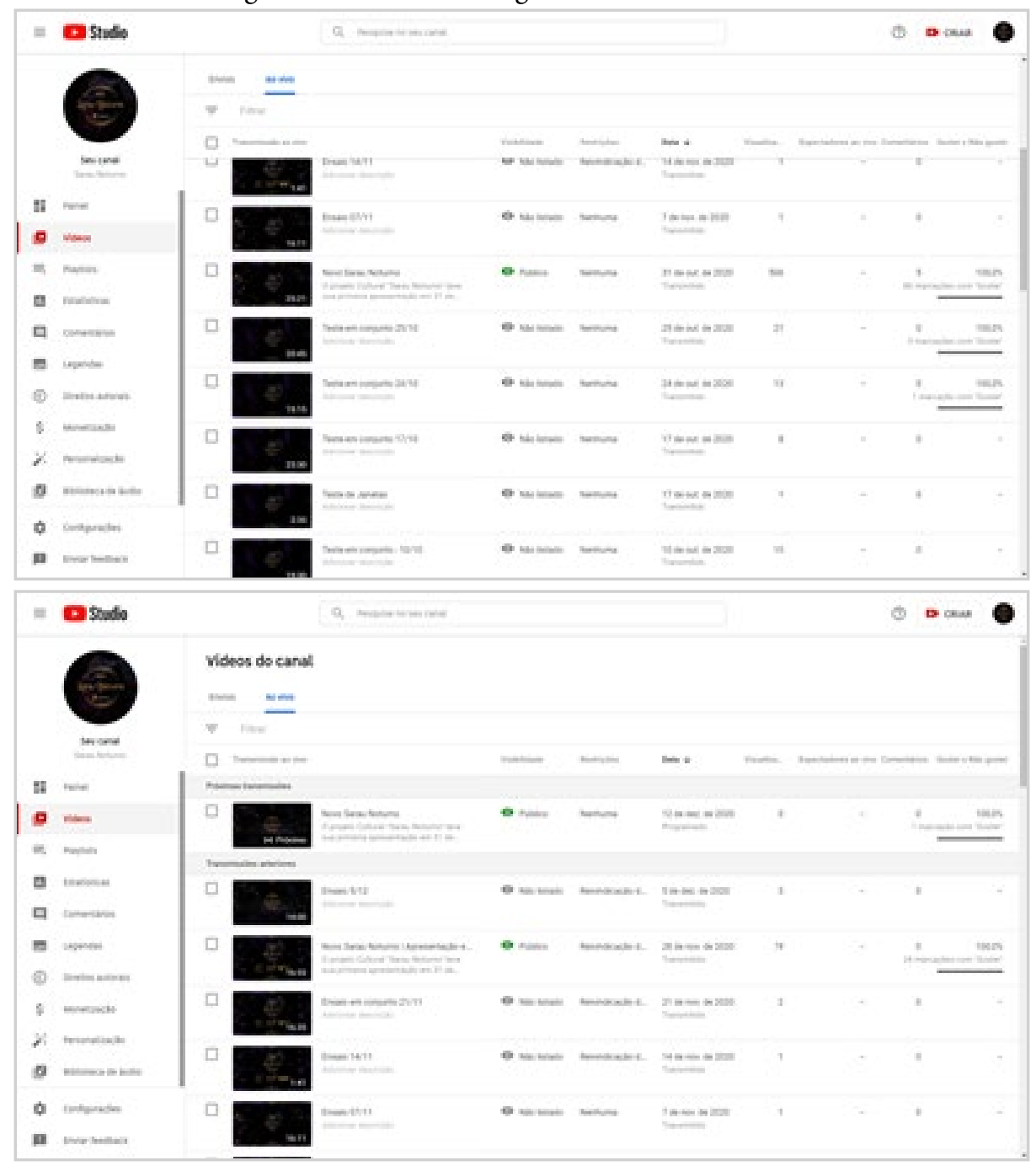

Fonte: Acervo do projeto.

Mas, como prender a atenção dos telespectadores? E, principalmente, como promover, instigar e estimular aqueles que conhecem o projeto do meio presencial e os que o desconhecem para esta nova proposta?

Tomando como ponto de partida a concepção visual necessária para o construto como um todo, ou seja, a identidade escolhida para a apresentação, e a vontade de ambientar o espectador, foram criados cenários, para cada personagem, que ressaltam o 
caráter simbólico presente em suas falas. Estes artifícios, somados ao esforço de adaptar a interpretação dos personagens ao enquadramento digital, trabalham em conjunto para com o produto final, o projeto reinventado através de seu roteiro para o meio virtual.

O novo Sarau Noturno foi lançado via plataforma virtual do YouTube no dia 31 de outubro de 2020, totalmente adaptado ao mundo virtual (Figura 7 e 8 ).

Figuras 7 e 8: Apresentação do dia 31 de outubro de 2020.
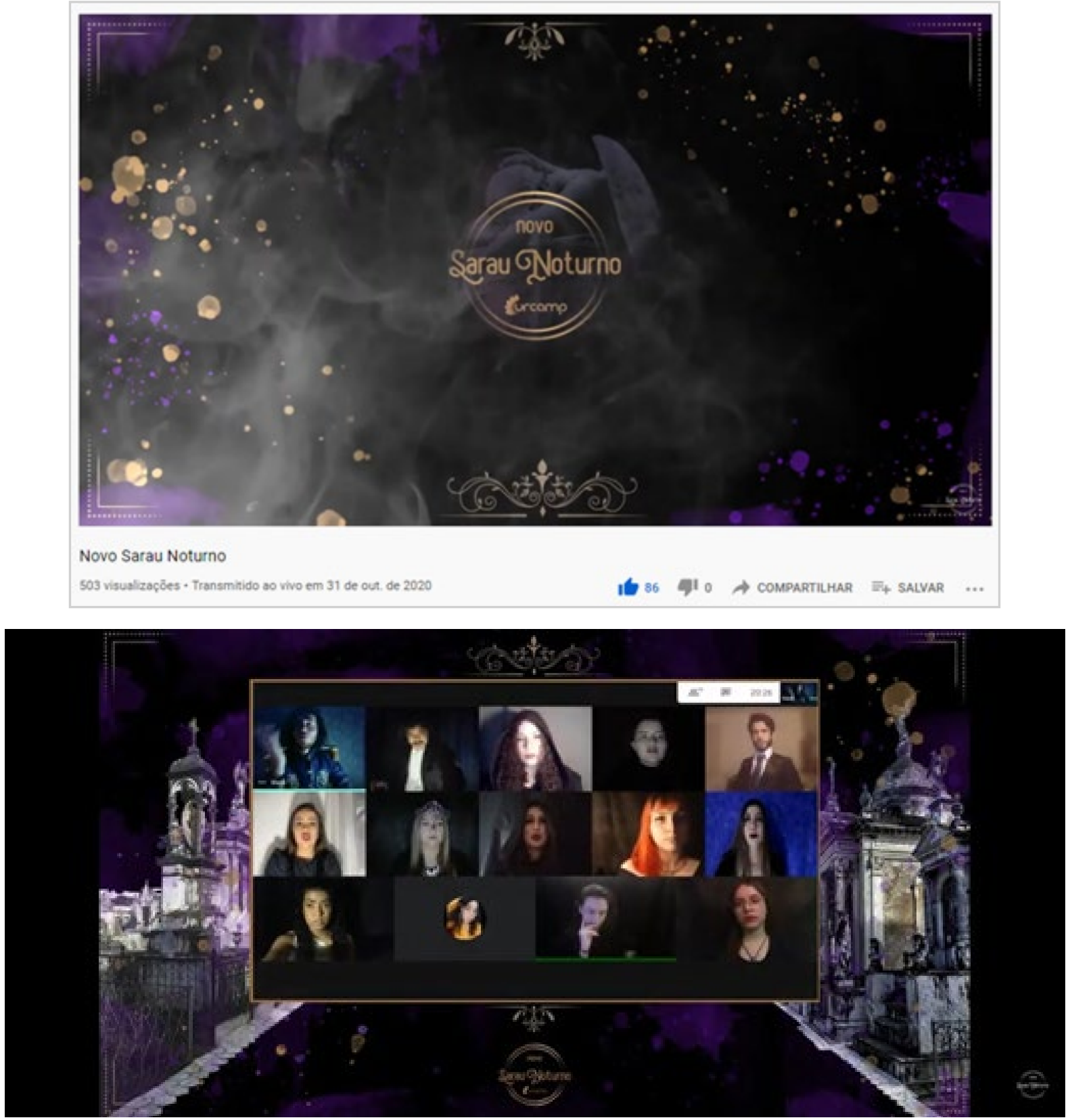

Fonte: Arquivo do projeto. Disponível em: <https://youtu.be/fiF9n3gsmGk>.

A primeira apresentação teve um público bastante expressivo, composto por 178 assistentes, dos quais professores, coordenadores, alunos da Urcamp, comunidade de Bagé. Destacamos abaixo algumas das manifestações proferidas durante a apresentação.

E como a gravação fica disponível, possibilitou um acesso ainda maior, sendo 
que hoje temos 544 visualizações. Os comentários foram bastante motivadores como o de Daniel Sperb, consultor da Urcamp.

\begin{abstract}
O mundo precisa conhecer esse lindo projeto! Meus parabéns!!!!!!!!!!! Clarisse, és a Maestrina dessa competente orquestra! Ver esses estudantes protagonizando seu próprio aprendizado é algo que leva qualquer educador que sabe o valor da educação libertadora às lágrimas! Clarisse, por favor, leve meus parabéns a todos talentos que presenciei nessa linda obra! Durante muitos anos eu pedi aos meus alunos que jamais entregassem um trabalho, mas sim, se entregassem ao trabalho. É isso! É isso que eu vi aqui! Meus parabéns, mais uma vez! (SPERB, Daniel Q. Depoimento via YouTube do Sarau Noturno, 2020).
\end{abstract}

Ocorreram mais duas apresentações, sendo uma especial para o Programa Institucional de Bolsas de Iniciação à Docência - PIBID e Residência Pedagógica da Urcamp (Figura 11), a convite da coordenadora institucional, professora Ângela Carretta. Ao final da apresentação, ocorreu uma conversa, via plataforma do Google Meet, sobre educação patrimonial e concepção dos personagens. E no dia 12 de dezembro encerramos a temporada de 2020.

Figura 11: Apresentação especial para os Programas PIBID

e Residência Pedagógica da Urcamp e Apresentação de encerramento do semestre.

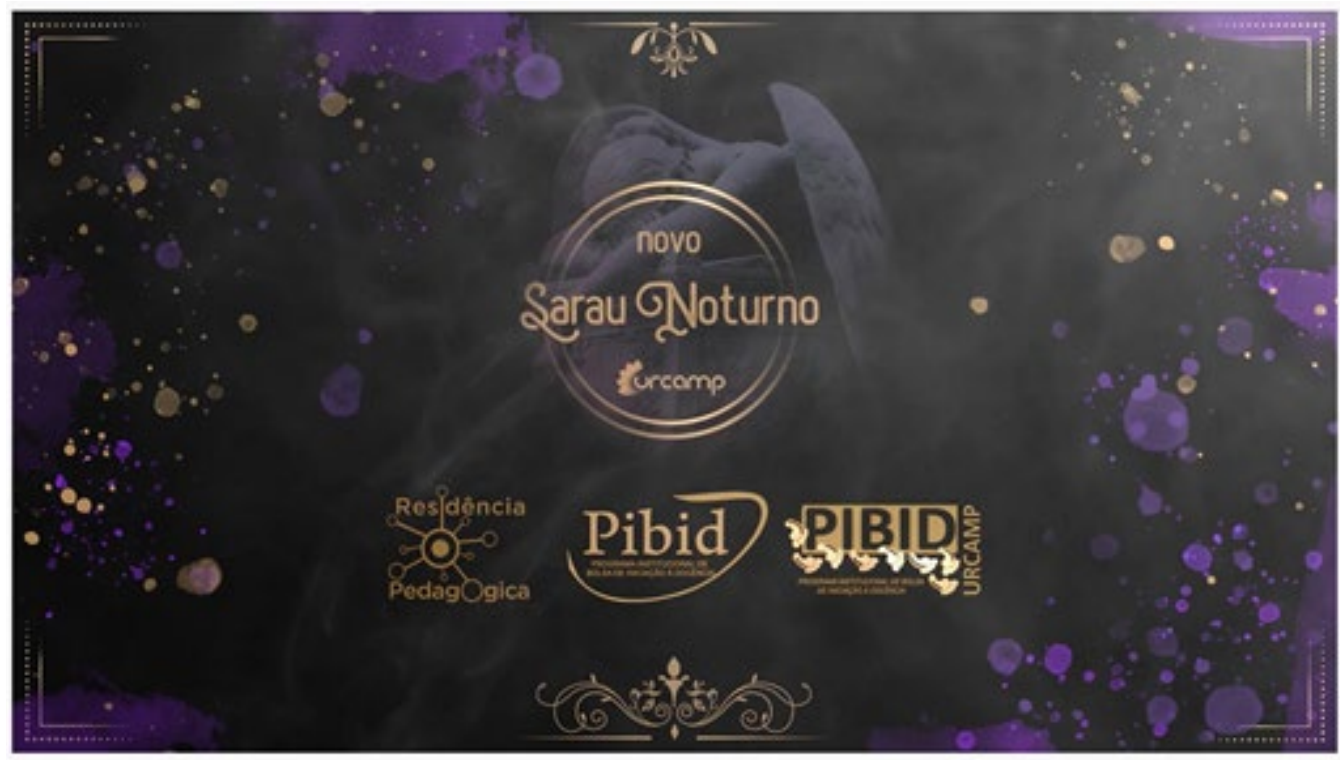

Novo Sarau Noturno | Apresentaçāo especial PIBID e Residẻncia Pedagógica URCAMP

80 visualizaçōes - Tranșmitido ao vivo em 28 de nov, de 2020

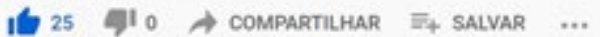

Fonte: Arquivo do projeto. Disponível: <https://youtu.be/pwSP6YOgayg $>$.

Destacamos que o grupo superou as dificuldades e proporcionou uma reinvenção do projeto frente às adversidades do novo veículo, buscando inovar e atender as necessidades de uma unidade visual e qualidade sonora que fora posteriormente aperfeiçoada de forma ainda mais efetiva. Por se caracterizar como um coletivo, as dificuldades individuais, como a integridade da conexão à internet e o alinhamento nos ensaios, precisaram ser superados em conjunto. O que não só qualificou o grupo, como gerou estímulos para seguir consagrando e firmando território na nova concepção e ressignificação do projeto nesse momento atípico. 


\section{Considerações finais}

Reinventar um evento consagrado não é uma tarefa fácil, ainda mais o Sarau Noturno, que era realizado presencialmente no Cemitério da Santa Casa de Caridade de Bagé desde 2008 e que possui reconhecimento da comunidade local e respaldo científico da área.

E, como relatado e evidenciado, foi um processo permeado pela restruturação do roteiro, ensaios, virtualização dos túmulos, construção do cenário virtual, criação e divulgação do material de divulgação, até chegar ao esperado dia 31 de outubro, no qual ocorreu a estreia do novo Sarau Noturno.

Para essa conquista, foi imprescindível o protagonismo dos acadêmicos, que tomaram para si o desafio da reconstrução e foram determinantes no êxito do projeto. Esses jovens desenvolveram competências e habilidades cognitivas que vão além dos seus cursos de formação.

O novo Sarau Noturno inova ao romper as barreiras físicas e levar sua mensagem de valorização e preservação da arte cemiterial para o interior das residenciais do público que o acompanha. A adaptação aos novos tempos é, sem dúvida nenhuma, mais uma proposta pioneira do projeto. Vida longa ao Sarau Noturno!

\section{Referências}

ARIÈS, Philipe. 1982. O Homem diante da morte. Rio de Janeiro: Francisco Alves, Vol. II, 1982.

BEllomo, Harry. Cemitérios do Rio Grande do Sul: arte, sociedade, ideologia. Porto Alegre: EDIPUCS, 2000.

CALDEIRA, Jeane dos Santos. O Asilo de Órfãs São Benedito em Pelotas - RS (as primeiras décadas do século $\mathrm{XX}$ ): trajetória educativa-institucional. Dissertação (Mestrado em Educação) - Universidade Federal de Pelotas, Pelotas, Rio Grande do Sul, 2014. Disponível em: <http://guaiaca.ufpel.edu.br:8080/handle/ri/2809>. Acesso em : 20 ago. 2020.

HORTA, Maria de Lourdes Parreiras. Fundamentos da educação patrimonial. Ciências e Letras, Porto Alegre, n. 27, 2000. p. 25-35.

ISMÉRIO, Clarisse. Sarau Noturno. Lisboa: Editora Chiado, 2016.

QUEIROZ, Francisco. Os cemitérios históricos e o seu potencial turístico em Portugal. In: Anuário 21 Gramas, n. 1, 2008, p. 7-12. Disponível em: <http://www.franciscoqueiroz.com/Cemiterios_ historicos_Potencial_Turistico_Portugal_\%20versao_21_gramas.pdf>.Acesso em: 31 maio 2016. 
